\title{
Patients with non-colorectal cancers may be at elevated risk of colorectal neoplasia
}

Hamzah Abu-Sbeih ${ }^{1}$, Faisal S. Ali², Wei Qiao ${ }^{3}$, Phillip Lum ${ }^{1}$, Mehnaz A. Shafi ${ }^{1}$, Robert S. Bresalier ${ }^{1}$, Ernest

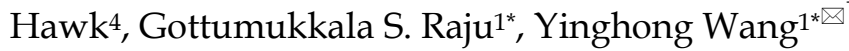

1. Department of Gastroenterology, Hepatology, and Nutrition, The University of Texas MD Anderson Cancer Center, Houston, Texas, USA.

2. Department of Internal Medicine, Presence Saint Joseph Hospital, Chicago, IL, USA.

3. Department of Biostatistics, The University of Texas MD Anderson Cancer Center, Houston, Texas, USA.

4. Department of Clinical Cancer Prevention, The University of Texas MD Anderson Cancer Center, Houston, Texas, USA.

*co-senior authors

$\triangle$ Corresponding author: Dr. Yinghong Wang, Department of Gastroenterology, Hepatology and Nutrition, The University of Texas MD Anderson Cancer Center, 1515 Holcombe Blvd., Unit 1466, Houston, TX 77030. Tel: (713) 794-5073. Fax (713) 794-5398. E-mail: ywang59@mdanderson.org.

(C) The author(s). This is an open access article distributed under the terms of the Creative Commons Attribution License (https://creativecommons.org/licenses/by/4.0/). See http://ivyspring.com/terms for full terms and conditions.

Received: 2019.09.27; Accepted: 2020.01.20; Published: 2020.03.04

\begin{abstract}
Background: Screening for colonic neoplasia has decreased the incidence of colorectal cancer in the United States in the past two decades. Whether personal history of noncolorectal cancer is a risk factor for colonic neoplasia has not been well studied. We assessed the risk of colorectal neoplasia in noncolorectal cancer survivors.

Methods: We conducted a retrospective study of patients who had undergone colonoscopy for any indication between 2009 and 2018. Colonic adenoma detection rate and multivariate logistic regression were conducted to assess for the primary outcomes of the study.

Results: The study included 9408 cancer patients and 3295 control patients. Colonic adenomas were detected in 4503 cancer patients (48\%) and 950 cancer-free patients (29\%). Histologic examination of these adenomas revealed tubulovillous features in 620 patients (5\%) and villous in $153(1 \%)$. High-grade dysplasia was detected in 1611 patients (13\%). Invasive colorectal adenocarcinoma was detected in 455 patients (12\%); this rate was highest in patients with multiple myeloma (14\%). Multivariate analysis revealed that a personal history of noncolorectal cancer was associated with increased risk of adenoma (Odd ratio, 2.04; 95\% Cl, 1.84-2.26; $P<0.001$ ). The adenoma detection rate was $30 \%$ in patients younger than 40 years $(n=1211), 32 \%$ in patients between 41 and 50 years $(n=812), 47 \%$ in patients between 51 and 60 years $(n=2892)$, and $55 \%$ in patients older than 60 years $(n=4493)$.

Conclusions: The adenoma detection rate in patients with a personal history of noncolorectal cancer is higher than the reported rate of the general population and our control group.
\end{abstract}

Key words: colorectal neoplasia, colon adenoma, adenoma detection rate, colorectal cancer, screening, surveillance

\section{Introduction}

Colorectal cancer (CRC) is the second leading cause of cancer-related death among both men and women, with 14.5 deaths per 100,000 adults and a 5-year survival rate of $65.5 \%$ in the United States [1]. The incidence of CRC in the United States has continued to decrease over the past 2 decades following the implementation of screening colonoscopies for colonic adenomatous polyps (CAP), which can be premalignant lesions, along with individual risk stratification for CRC [2,3]. Colonoscopy allows for early detection and removal of CAP or early-stage CRC. Additionally, the advent of advanced endoscopic treatment for CAP, even large ones $(>10 \mathrm{~mm})$, has decreased the need for surgical intervention and lowered the morbidity and mortality associated with open intra-abdominal 
interventions [4]. The implementation of CRC screening efforts, including colonoscopy, has recently been shown to be highly cost-effective over a patient's lifetime [5].

The current recommendations favor screening patients at average risk for CRC when they are 50 years old [6-8]. When risk factors associated with early CRC are identified, such as a personal or family history of CRC, CAP, hereditary colonic polyposis syndromes, or inflammatory bowel disease, screening colonoscopies are initiated prior to 50 years of age $[6,9]$. Several other risk factors for CRC have been proposed including obesity, smoking, male sex, heavy alcohol consumption, lack of physical activity, and lack of nutrients and vitamins $[10,11]$. However, none of these proposed risk factors currently warrant early screening colonoscopies.

There has been concern regarding the possible association between noncolorectal cancers (NCRC) and CAP and CRC [50-52]. The current body of evidence on this topic reveals conflicting results $[12,13]$. The potential link between NCRC and CRC may be explained by a commonality in the genetic and molecular predispositions to cancer, particularly since a variety of cancers share the same cascade of events that lead to their progression from non-neoplastic tissue to a neoplastic process. CAP can progress to CRC by 2 different pathways involving inherited and acquired genetic mutations of the adenomatous polyposis coli (APC), KRAS, TP53, and $B R A F$ genes [14-18]. Additionally, microsatellite instability caused by alterations in DNA mismatch repair genes plays a pivotal role in the development of CRC [18] and has been identified in 27 other tumor types [19]. Thus, associations between NCRC and $\mathrm{CRC}$ or its precursor, CAP, are possible and warrant further investigation. In our clinical practice at a tertiary cancer center, we noticed a high adenoma detection rate (ADR) among patients with personal history of NCRC. However, the current body of evidence addressing the risk of CRC or CAP after NCRC diagnosis is scarce.

The purpose of this study was to determine whether an association exists between NCRC and CRC or CAP. We also aimed to characterize the histologic features of CAP among patients at a tertiary cancer center with a history of NCRC.

\section{Methods and Materials}

\section{Patient population}

This retrospective study was conducted after obtaining approval from the institutional review board at The University of Texas MD Anderson Cancer Center. We included patients who had undergone their first colonoscopic evaluation for any indication between 2009 and 2018. Patients with a personal history of CRC, CAP, inflammatory bowel disease, or hereditary polyposis syndromes were excluded. Also, patients who underwent their first colonoscopy before the diagnosis of cancer were excluded. Patients were identified from endoscopy databases (EndoWorks, Center Valley, PA and later, Provation, Minneapolis, MN) at our institution using natural language processing [20]. Then, data pertaining to this study were extracted from institutional databases.

\section{Clinical data}

We obtained information regarding demographics and the presence, type, and treatment of cancer from the institutional tumor registry. Variables relating to medical history were collected from electronic medical charts. Demographics consisted of age, sex, race or ethnicity, and body mass index (BMI) at the time of the initial colonoscopy after cancer diagnosis. Family history of CRC in a first-degree relative and active or previous tobacco use were recorded. Patients were categorized into 2 groups, cancer or no-cancer, based on the presence of confirmed malignancy at the time of initial endoscopic screening. Cancer types were classified according to site, system, or cell lineage owing to the large number of cancer types, numerous classifications, and limited space to divide them further.

\section{Endoscopy and histology}

In patients with polyps evident on colonoscopy, biopsies were taken to prove the presence of adenoma histologically. Endoscopic procedures with poor bowel preparation (Boston Bowel Preparation score lower than 2 for the examined regions of the colon) [21] or with severe colonic inflammation obscuring full examination of the colon were excluded. Histopathology reports were studied to document the presence of advanced adenoma features, such as villous or tubulovillous features or high-grade dysplasia, or advanced adenocarcinoma.

\section{Statistical analyses}

Continuous variables were described using mean and standard deviation (SD) or median and interquartile range (IQR). Categorical variables were summarized using frequencies and percentages. Continuous variables were compared between 2 groups using the Wilcoxon rank sum test. Categorical variables were compared between groups using the Fisher exact or $\chi^{2}$ test. We performed multivariate logistic regression analysis to assess for risk factors associated with detection of CAP. Statistical tests were 
2-sided. $P$ values lower than 0.05 were considered significant. Statistical analyses were carried out using SAS version 9.4 (SAS Institute, Cary, NC) and SPSS version 24.0 (SPSS, Inc., Chicago, IL).

\section{Results}

\section{Included patients}

A total of 12703 patients had their first colonoscopy between 2009 and 2018. Colonoscopy was performed for CRC screening in 8252 patients, for GI symptoms in 3634, and for primary cancer assessment in 817. Most patients were female (55.1\%). The mean age was 57 years (SD, 13 years). Most patients were white $(68.2 \%)$, followed by black $(10.8 \%)$ and Hispanic $(9.0 \%)$. A history of smoking was reported in $37.4 \%$ of patients, and a family history of CRC was reported in $19.7 \%$. The mean BMI at the time of first colonoscopy was $29.4 \mathrm{~kg} / \mathrm{m}^{2}$ (SD, 6.6 $\mathrm{kg} / \mathrm{m}^{2}$ ). A diagnosis of NCRC was present in 9408 patients, whereas 3295 had no cancer diagnosis. Clinical features of both groups are listed in Table 1.

Table 1. Characteristics of patients with and without a history of noncolorectal cancer at the time of first colonoscopy

\begin{tabular}{|c|c|c|c|}
\hline Characteristic & $\begin{array}{l}\text { Cancer, No. (\%) (n } \\
=9408)\end{array}$ & $\begin{array}{l}\text { No Cancer, No. } \\
(\%)(\mathrm{n}=3295)\end{array}$ & $P$ \\
\hline Age, y, mean (SD) & $58(13)$ & $54(11)$ & $<0.001$ \\
\hline Male sex & $4401(46.8)$ & $1307(39.7)$ & $<0.001$ \\
\hline Race $^{\mathrm{a}}$ & & & $<0.001$ \\
\hline White & $6462(68.7)$ & $2201(67.0)$ & \\
\hline Black & $966(10.3)$ & $399(12.1)$ & \\
\hline Hispanic & $949(10.1)$ & $189(5.8)$ & \\
\hline Asian & $401(4.3)$ & $364(11.1)$ & \\
\hline Other & $630(6.7)$ & $133(4.0)$ & \\
\hline $\begin{array}{l}\text { Family history of colorectal } \\
\text { cancer }\end{array}$ & $1518(16.1)$ & $989(30.0)$ & $<0.001$ \\
\hline Smoking history & $3953(42.0)$ & $800(24.3)$ & $<0.001$ \\
\hline $\begin{array}{l}\text { BMI at time of colonoscopy, } \\
\mathrm{kg} / \mathrm{m}^{2}, \text { mean }(\mathrm{SD})^{\mathrm{b}}\end{array}$ & $29.5(6.6)$ & $29.2(6.4)$ & 0.120 \\
\hline
\end{tabular}

\section{Patients with CAP}

CAP was detected in 5453 (42.9\%) patients: 4503 NCRC patients (48\%) and 950 cancer-free patients (29\%). Characteristics of patients with and without CAP are compared in Table 2. The median time from cancer diagnosis to CAP detection was 3 years (IQR, 1-8). On multivariate logistic regression analysis, the following factors were associated with increased risk of CAP: older age (odd ratio [OR], 1.03; 95\% confidence interval [CI], 1.03-1.04; $P<0.001$ ), male sex (OR, 1.49; 95\% CI, 1.37-1.62; $P<0.001$ ), family history of CRC (OR, 1.38; 95\% CI, 1.25-1.54; $P<0.001)$, high BMI (OR, 1.03; 95\% CI, 1.02-1.03; $P<0.001$ ), and personal history of NCRC $(2.04 ; 95 \%$ CI, 1.84-2.26; $P<$ 0.001 ; Table 3). The ADR was $49.8 \%$ for patients who underwent colonoscopy for CRC screening and 30.2\% for patients who underwent colonoscopy for other indications $(P<0.001)$.

Table 2. Characteristics of patients with and without adenomatous polyps detected on colonoscopy

\begin{tabular}{|c|c|c|c|}
\hline Characteristic & $\begin{array}{l}\text { Adenoma, No. } \\
(\%)(\mathrm{n}=5453)\end{array}$ & $\begin{array}{l}\text { No Adenoma, No. } \\
(\%)(\mathrm{n}=7250)\end{array}$ & $P$ \\
\hline Age, $y$, mean (SD) & $60(12)$ & $55(13)$ & $<0.001$ \\
\hline Male sex & $2785(51.1)$ & $2923(40.3)$ & $<0.001$ \\
\hline Race $^{\mathrm{a}}$ & & & 0.025 \\
\hline White & $3756(68.9)$ & 4907 (67.7) & \\
\hline Black & $610(11.2)$ & $755(10.4)$ & \\
\hline Hispanic & $470(8.6)$ & $668(9.2)$ & \\
\hline Asian & $291(5.3)$ & $474(6.5)$ & \\
\hline Other & $324(5.9)$ & $439(6.1)$ & \\
\hline $\begin{array}{l}\text { Family history of colorectal } \\
\text { cancer }\end{array}$ & $1084(19.9)$ & $1423(19.6)$ & 0.736 \\
\hline Smoking history & $2183(40.0)$ & $2570(35.4)$ & $<0.001$ \\
\hline $\begin{array}{l}\text { BMI at time of colonoscopy, } \\
\mathrm{kg} / \mathrm{m}^{2}, \text { mean }(\mathrm{SD})^{\mathrm{b}}\end{array}$ & $30.0(6.6)$ & $28.9(6.6)$ & $<0.001$ \\
\hline Cancer & & & $<0.001$ \\
\hline Yes & $4503(82.6)$ & 4905 (67.7) & \\
\hline No & $950(17.4)$ & $2345(32.3)$ & \\
\hline Cancer type & & & $<0.001$ \\
\hline Breast & $1012(22.5)$ & $1028(21.0)$ & \\
\hline Prostate & $780(17.3)$ & $436(8.9)$ & \\
\hline Lymphoma & $452(10.0)$ & $650(13.3)$ & \\
\hline Leukemia & $218(4.8)$ & $748(15.2)$ & \\
\hline Non-melanoma skin & $299(6.6)$ & $258(5.3)$ & \\
\hline Vulvovaginal and uterus & $246(5.5)$ & $281(5.7)$ & \\
\hline Melanoma & $229(5.1)$ & $244(5.0)$ & \\
\hline Head and neck & $246(5.5)$ & $165(3.4)$ & \\
\hline Lung & $176(3.9)$ & $147(3.0)$ & \\
\hline Endocrine & $132(2.9)$ & $152(3.1)$ & \\
\hline Multiple myeloma & $153(3.4)$ & $170(3.5)$ & \\
\hline Kidney & $117(2.6)$ & $101(2.1)$ & \\
\hline Urothelial & $103(2.3)$ & $100(2.0)$ & \\
\hline Soft tissue & $89(2.0)$ & $104(2.1)$ & \\
\hline Ovary & $86(1.9)$ & $161(3.3)$ & \\
\hline Liver & $75(1.7)$ & $62(1.3)$ & \\
\hline Pancreas & $53(1.2)$ & $63(1.3)$ & \\
\hline Unknown primary & $37(0.8)$ & $35(0.7)$ & \\
\hline \multicolumn{4}{|c|}{$\begin{array}{l}\text { aInformation for race was not available in } 2 \text { patients in Adenoma group, and } 7 \\
\text { patients in No adenoma group; }\end{array}$} \\
\hline
\end{tabular}

Table 3. Multivariate logistic regression for adenoma detection.

\begin{tabular}{llll}
\hline & Odds Ratio & 95\% Confidence Interval & $\boldsymbol{P}$ \\
\hline Age & 1.03 & $1.03-1.04$ & $<0.001$ \\
Male sex & 1.49 & $1.37-1.62$ & $<0.001$ \\
Family history of colorectal cancer & 1.38 & $1.25-1.54$ & $<0.001$ \\
Smoking history & 0.97 & $0.89-1.05$ & 0.426 \\
BMI & 1.03 & $1.02-1.03$ & $<0.001$ \\
Cancer & 2.04 & $1.84-2.26$ & $<0.001$ \\
\hline Abbreviation: BMI, body mass index & &
\end{tabular}

\section{ADR by cancer type and age}

The numbers of patients and the ADR in different age groups stratified by cancer type are shown in Supp. Table 1 and Figure 1. In patients younger than 40 years, the ADR was the highest in patients with prostate cancer $(54.3 \%)$ and non-melanoma skin cancer $(54.1 \%)$, followed by head and neck cancer $(50.0 \%)$. In patients between ages 41 
and 50 years, those with prostate cancer had the highest ADR (58.8\%), followed by those with head and neck cancer (56.0\%) and kidney cancer (53.3\%). In patients between ages of 51 and 60 years, those with liver cancer had the highest ADR (72.5\%), followed by patients with prostate cancer $(69.0 \%)$ and those with cancer of an unknown primary source $(66.7 \%)$. In patients older than 60 years, those with prostate cancer $(64.1 \%)$ and head and neck cancer $(63.9 \%)$ had the highest ADRs.

\section{Histologic features of adenoma}

Overall, high-grade dysplasia was reported in 1,611 patients $(12.7 \%)$ whereas $620(4.9 \%)$ patients had tubulovillous adenomas and $153(1.2 \%)$ had villous adenomas. High-grade dysplasia was most commonly detected in patients with lung cancer (41.5\%; Figure 2), followed by ovarian cancer (38.4\%). Adenocarcinoma was diagnosed in 455 patients $(3.6 \%)$. Of note, the highest proportion of adenocarcinoma detection was in patients with multiple myeloma $(14.4 \%)$, followed by ovarian cancer $(12.8 \%)$ and lung cancer $(10.8 \%)$.

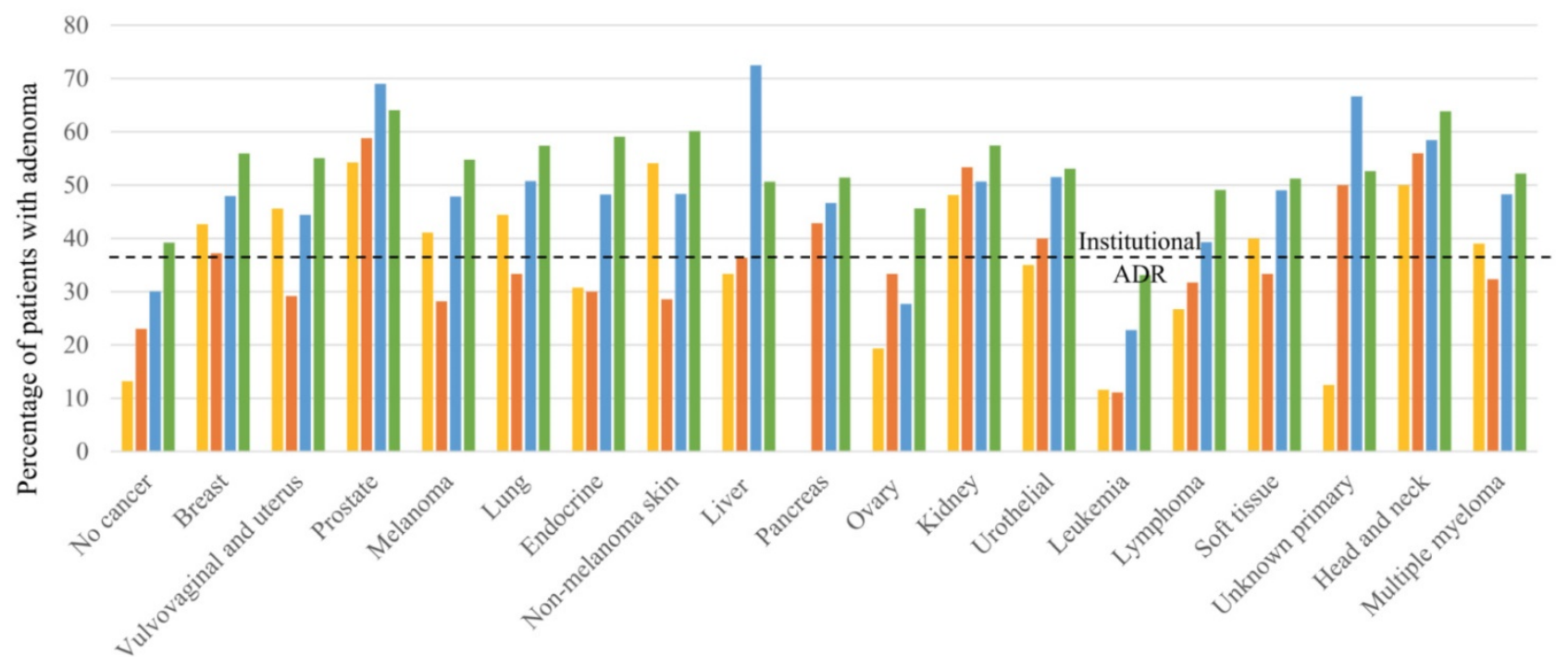

Figure 1. Adenoma detection rates in patients grouped by age and cancer type.

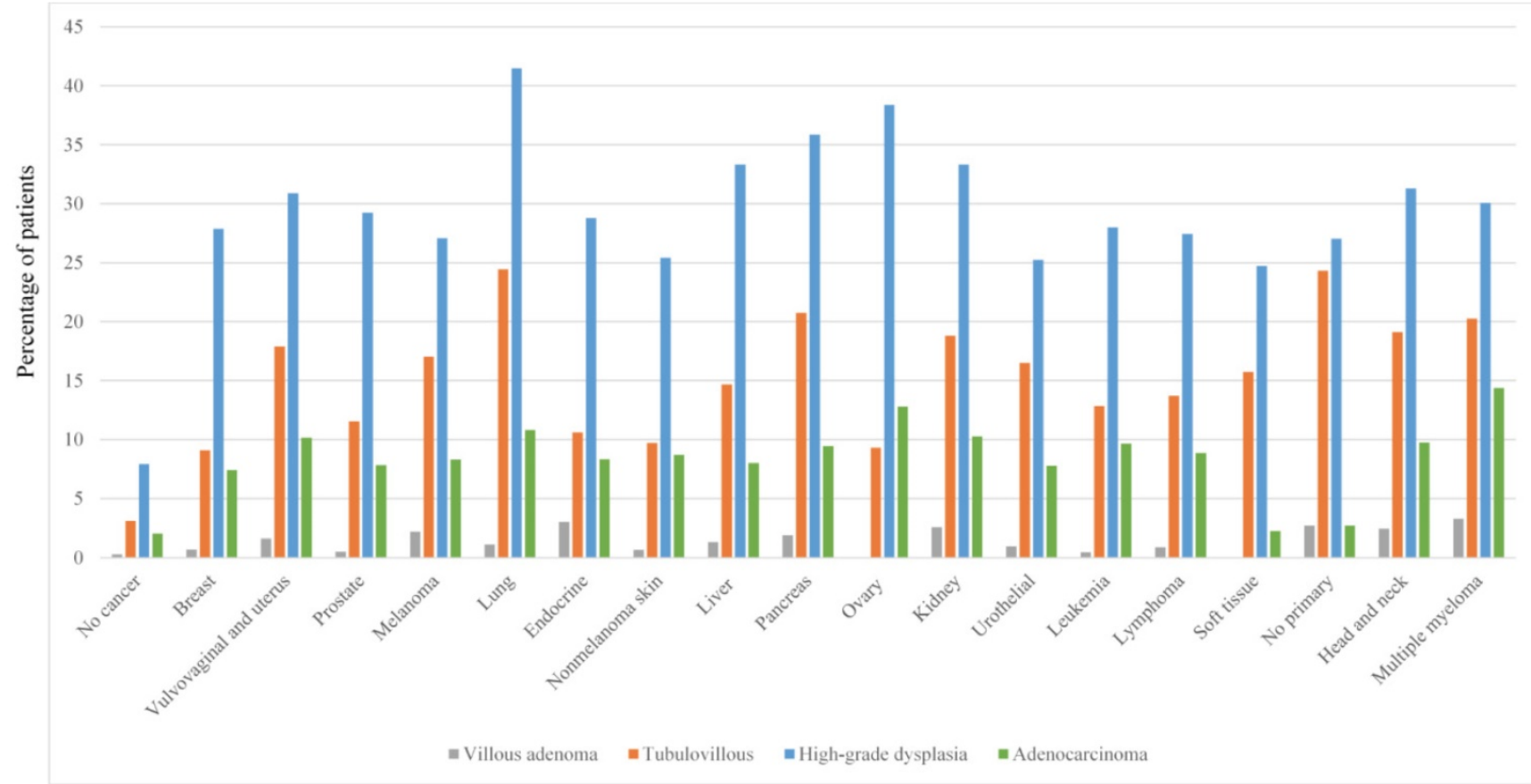

Figure 2. Advanced adenoma features grouped by cancer type. 


\section{Discussion}

This study characterizes the incidence, histologic features, and risk of CAP in patients with a personal history of NCRC. Among patients with a history of NCRC, we found an ADR of $46 \%$, with the highest rates observed among patients with a history of prostate cancer, non-melanoma skin cancer, head and neck cancer, and kidney cancer. The $46 \%$ ADR was greater than that of the control group or the general population at our institution. A low gastroenterologist turnover rate ensures consistency in our institutional $\mathrm{ADR}$, and this consistency strengthens the implications of our findings. We found a personal history of NCRC to be an independent risk factor for CAP. With a $12.7 \%$ incidence of high-grade dysplasia and a $3.6 \%$ incidence of adenocarcinoma, our findings weigh in favor of lowering the age for initial CRC screening for NCRC patients.

Upon stratifying CAP incidence by age, we found that ADR tended to increase with age for most cancers. For individuals between 40 to 50 years with prostate cancer, the ADR was higher than it was for prostate cancer patients younger than 40 years. A similar trend of increased ADR with increasing age was observed among patients with pancreatic cancer, kidney cancer, urothelial cancer, head and neck cancer, and lymphoma. This trend highlights the impact of aging on the incidence of CAP and is in concordance with the significance of old age as an independent risk factor for the development of CAP. The high ADRs found among individuals younger than 50 years with certain cancers, such as prostate cancer and non-melanoma skin cancer, are concerning and warrant further investigation into the mechanisms behind the association between NCRC and CAP, which currently is a poorly studied issue. Additionally, the high ADRs among patients younger than 50 years highlight the importance of early screening colonoscopy among patients with a history of NCRC.

Previously reported studies regarding the risk of CRC are limited to certain types of NCRC and show inconsistent results $[12,13]$. Little is known about the association between NCRC and CRC in the United States, and our study characterizes the incidence of CRC among a sample of American patients with a history of NCRC. We found advanced adenocarcinoma in $3.6 \%$ of the patients, with the highest incidence in patients with multiple myeloma, followed by ovarian cancer and lung cancer. CRC and NCRC share a considerable number of risk factors to which their association can be attributed.

One important component implicated in the cascade of events that lead to oncogenesis in CRC is the plethora of genetic mutations, some of which can also be present in patients with NCRC. The mutation in $A P C$, a tumor suppressor gene that is a hallmark of some CRCs, was reported by Liberman and colleagues to be detected in NCRC as well [22]. Likewise, a mutation in the KRAS proto-oncogene facilitates the second step in the carcinogenesis of 1 subtype of CRC.[23] This alteration plays a pivotal role in some NCRCs' pathogenesis as well [24-26]. Mutations in the TP53 and BRAF genes have been implicated in the development of CRC as well as NCRC [27-30].

Associations between CRC and breast, ovarian, and uterine cancers have been reported in previous studies [31-35]. Hormonal influences have been suggested to explain these observed associations, though it is not evident whether these hormonal influences act similarly in the context of CRC as they do in the development of breast, ovarian, and uterine cancers [36-38]. The potential role of hormonal influences is further strengthened by the reported mitigation of CRC risk among patients receiving hormone replacement therapy, especially after menopause, and patients receiving estrogen receptor modulators [39-42].

Among the more established risk factors for CRC are obesity, old age, physical inactivity, dietary habits, alcohol use, and smoking $[10,43]$. Cancer treatments such as chemotherapy and radiotherapy have also been implicated in the development of CRC [44-49]. These risk factors can also predispose patients to a variety of NCRCs and may explain the commonality among these cancers. Intuitively, the association between NCRC and CAP may be more obvious in patients with a higher risk factor burden. Our analysis found a higher BMI to be associated with CAP detection. However, smoking was not found to have an independent association with CAP detection. The retrospective nature of our study limited our ability to analyze and account for additional known risk factors for CRC and NCRC. This highlights the need for efforts to analyze the factors potentiating the risk of CRC in patients with NCRC.

Our study has noteworthy limitations. First, the retrospective nature of our analysis limits the accuracy of our data. Second, our results might not be generalizable as they were based on data from a single center. Third, some of the colonoscopies in our study had been done for indications other than screening; this could affect the ADR. Fourth, we grouped all cancer types together in the multivariate analyses, and a separate analysis for each individual cancer type was not performed. This grouped analysis allowed us to characterize the CAP incidence rate but limited our ability to make recommendations 
regarding the appropriate timing for screening colonoscopy for specific cancer types. Since it is evident that the ADR is higher among certain cancers, the appropriate timeframe for screening colonoscopy after the diagnosis of each NCRC needs to be outlined in future studies. Last, although our study had a large sample size, in certain subgroup analyses our samples were underpowered.

\section{Conclusions}

Our analysis revealed that patients with a personal history of NCRC had a higher ADR than did patients without a history of NCRC. The ADR is higher in certain cancers, including prostate cancer, head and neck cancer, kidney cancer, and nonmelanoma skin cancer. The higher risk in these NCRCs warrants further studies of these individual cancers separately. Patients with a history of NCRC may benefit from screening for CRC earlier than 50 years of age. Future large-scale studies stemming from national or multicenter databases are warranted to further validate our findings and to investigate the appropriate timing for CRC screening as well as the appropriate interval for follow-up colonoscopy.

\section{Supplementary Material}

Supplementary table.

http://www.jcancer.org/v11p3192s1.pdf

\section{Acknowledgements}

Medical editing of this paper was provided by the Department of Scientific Publications at MD Anderson Cancer Center.

\section{Author Contributions}

YW and GSR were the senior authors of this study, developed the concept, interpreted the results, ensured that the accuracy and integrity of the data was preserved at all stages, agreed to be accountable for all aspects of this study, were in charge of the overall direction and planning of the study, and contributed to the writing of the manuscript with input from all authors.

HA collected the data for the study, designed the study, assessed to conduct and interpret the analysis, wrote the manuscript, and designed the figures.

FA assessed in writing and editing the paper.

WQ and PL processed the data and performed the statistical analysis.

MS, EH, and RSB revised critically the final version of the manuscript.

\section{Funding}

This study was not supported by any funding.

\section{Competing Interests}

The authors have declared that no competing interest exists.

\section{References}

1. Siegel R, Desantis C, Jemal A. Colorectal cancer statistics, 2014. CA Cancer J Clin 2014; 64: 104-117.

2. [Internet] American Cancer Society. Cancer Facts \& Figures 2015. Atlanta, GA: American Cancer Society. Accessed January 19, 2019. https://www.cancer.org/content/dam/cancer-org/research/cancer-facts-an d-statistics/annual-cancer-facts-and-figures / 2015/cancer-facts-and-figures-20 15.pdf

3. American Cancer Society. Colorectal Cancer Facts \& Figures 2011-2013. Atlanta, GA: American Cancer Society; 2011

4. Raju GS, Lum PJ, Ross WA et al. Outcome of EMR as an alternative to surgery in patients with complex colon polyps. Gastrointest Endosc 2016; 84: 315-325.

5. [Internet] Colorectal cancer screening highly cost effective in US. PharmacoEcon Outcomes News (2018) 806: 8. Springer International Publishing. Accessed January 19, $2019 \quad 30$ June 2018. https://doi.org/10.1007/s40274-018-5051-7

6. Rex DK, Johnson DA, Anderson JC et al. American College of Gastroenterology guidelines for colorectal cancer screening 2009 [corrected]. Am J Gastroenterol 2009; 104: 739-750.

7. Levin B, Lieberman DA, McFarland B et al. Screening and surveillance for the early detection of colorectal cancer and adenomatous polyps, 2008: a joint guideline from the American Cancer Society, the US Multi-Society Task Force on Colorectal Cancer, and the American College of Radiology. CA Cancer J Clin 2008; 58: 130-160.

8. Bibbins-Domingo K, Grossman DC, Curry SJ et al. Screening for Colorectal Cancer: US Preventive Services Task Force Recommendation Statement. Jama 2016; 315: 2564-2575.

9. Issa IA, Noureddine M. Colorectal cancer screening: An updated review of the available options. World J Gastroenterol 2017; 23: 5086-5096.

10. Brenner H, Kloor M, Pox CP. Colorectal cancer. Lancet 2014; 383: 1490-1502.

11. Song M, Garrett WS, Chan AT. Nutrients, foods, and colorectal cancer prevention. Gastroenterology 2015; 148: 1244-1260.e1216.

12. Schoen RE, Weissfeld JL, Kuller LH. Are women with breast, endometrial, or ovarian cancer at increased risk for colorectal cancer? Am J Gastroenterol 1994; 89: 835-842.

13. Newschaffer CJ, Topham A, Herzberg T et al. Risk of colorectal cancer after breast cancer. Lancet 2001; 357: 837-840.

14. Simon K. Colorectal cancer development and advances in screening. Clin Interv Aging 2016; 11: 967-976.

15. Bateman AC. Pathology of serrated colorectal lesions. J Clin Pathol 2014; 67: 865-874.

16. Kang GH. Four molecular subtypes of colorectal cancer and their precursor lesions. Arch Pathol Lab Med 2011; 135: 698-703.

17. O'Brien MJ, Yang S, Mack $C$ et al. Comparison of microsatellite instability, $\mathrm{CpG}$ island methylation phenotype, BRAF and KRAS status in serrated polyps and traditional adenomas indicates separate pathways to distinct colorectal carcinoma end points. Am J Surg Pathol 2006; 30: 1491-1501.

18. Boland CR, Goel A. Microsatellite instability in colorectal cancer. Gastroenterology 2010; 138: 2073-2087.e2073.

19. Bonneville R, Krook MA, Kautto EA et al. Landscape of Microsatellite Instability Across 39 Cancer Types. JCO Precis Oncol 2017; 2017.

20. Raju GS, Lum PJ, Slack RS et al. Natural language processing as an alternative to manual reporting of colonoscopy quality metrics. Gastrointest Endosc 2015; 82: 512-519.

21. Lai EJ, Calderwood AH, Doros $\mathrm{G}$ et al. The Boston bowel preparation scale: a valid and reliable instrument for colonoscopy-oriented research. Gastrointest Endosc 2009; 69: 620-625.

22. Liberman E, Kraus S, Sagiv E et al. The APC E1317Q and I1307K polymorphisms in non-colorectal cancers. Biomed Pharmacother 2007; 61: 566-569.

23. Hartman DJ, Davison JM, Foxwell TJ et al. Mutant allele-specific imbalance modulates prognostic impact of KRAS mutations in colorectal adenocarcinoma and is associated with worse overall survival. Int J Cancer 2012; 131: 1810-1817.

24. Sankaranarayanan P, Schomay TE, Aiello KA, Alter O. Tensor GSVD of patient- and platform-matched tumor and normal DNA copy-number profiles uncovers chromosome arm-wide patterns of tumor-exclusive platform-consistent alterations encoding for cell transformation and predicting ovarian cancer survival. PLoS One 2015; 10: e0121396.

25. Chen $Y, M c G e e ~ J, C h e n ~ X$ et al. Identification of druggable cancer driver genes amplified across TCGA datasets. PLoS One 2014; 9: e98293.

26. Krasinskas AM, Moser AJ, Saka B et al. KRAS mutant allele-specific imbalance is associated with worse prognosis in pancreatic cancer and progression to undifferentiated carcinoma of the pancreas. Mod Pathol 2013; 26: 1346-1354.

27. Hollstein M, Sidransky D, Vogelstein B, Harris CC. p53 mutations in human cancers. Science 1991; 253: 49-53. 
28. Maldonado JL, Fridlyand J, Patel $\mathrm{H}$ et al. Determinants of BRAF mutations in primary melanomas. J Natl Cancer Inst 2003; 95: 1878-1890.

29. Puxeddu E, Moretti S, Elisei $R$ et al. BRAF(V599E) mutation is the leading genetic event in adult sporadic papillary thyroid carcinomas. J Clin Endocrinol Metab 2004; 89: 2414-2420.

30. Tan YH, Liu Y, Eu KW et al. Detection of BRAF V600E mutation by pyrosequencing. Pathology 2008; 40: 295-298.

31. Lai JH, Park G, Gerson LB. Association between breast cancer and the risk of colorectal cancer. Gastrointest Endosc 2017; 86: 429-441.e421.

32. Lu Y, Segelman J, Nordgren A et al. Increased risk of colorectal cancer in patients diagnosed with breast cancer in women. Cancer Epidemiol 2016; 41: $57-62$.

33. Soerjomataram I, Louwman WJ, de Vries E et al. Primary malignancy after primary female breast cancer in the South of the Netherlands, 1972-2001. Breast Cancer Res Treat 2005; 93: 91-95.

34. Mellemkjaer L, Friis S, Olsen JH et al. Risk of second cancer among women with breast cancer. Int J Cancer 2006; 118: 2285-2292.

35. Teppo L, Pukkala E, Saxen E. Multiple cancer--an epidemiologic exercise in Finland. J Natl Cancer Inst 1985; 75: 207-217.

36. Gunter MJ, Hoover DR, Yu H et al. Insulin, insulin-like growth factor-I, endogenous estradiol, and risk of colorectal cancer in postmenopausal women. Cancer Res 2008; 68: 329-337.

37. Clendenen TV, Koenig KL, Shore RE et al. Postmenopausal levels of endogenous sex hormones and risk of colorectal cancer. Cancer Epidemiol Biomarkers Prev 2009; 18: 275-281.

38. Barzi A, Lenz AM, Labonte MJ, Lenz HJ. Molecular pathways: Estrogen pathway in colorectal cancer. Clin Cancer Res 2013; 19: 5842-5848.

39. Johnson JR, Lacey JV, Jr., Lazovich D et al. Menopausal hormone therapy and risk of colorectal cancer. Cancer Epidemiol Biomarkers Prev 2009; 18: 196-203.

40. Rennert G, Rennert HS, Pinchev M et al. Use of hormone replacement therapy and the risk of colorectal cancer. J Clin Oncol 2009; 27: 4542-4547.

41. Andersson M, Storm HH, Mouridsen HT. Incidence of new primary cancers after adjuvant tamoxifen therapy and radiotherapy for early breast cancer. J Natl Cancer Inst 1991; 83: 1013-1017.

42. Martineti V, Silvestri S, Tonelli F, Brandi ML. Control of colon cancer development and progression by selected estrogen receptor modulators. Expert Rev Endocrinol Metab 2008; 3: 503-511.

43. Harvey EB, Brinton LA. Second cancer following cancer of the breast in Connecticut, 1935-82. Natl Cancer Inst Monogr 1985; 68: 99-112.

44. Mazonakis M, Varveris C, Lyraraki E, Damilakis J. Radiotherapy for stage I seminoma of the testis: Organ equivalent dose to partially in-field structures and second cancer risk estimates on the basis of a mechanistic, bell-shaped, and plateau model. Med Phys 2015; 42: 6309-6316.

45. Nieder AM, Porter MP, Soloway MS. Radiation therapy for prostate cancer increases subsequent risk of bladder and rectal cancer: a population based cohort study. J Urol 2008; 180: 2005-2009; discussion 2009-2010.

46. Brenner DJ, Curtis RE, Hall EJ, Ron E. Second malignancies in prostate carcinoma patients after radiotherapy compared with surgery. Cancer 2000; 88: 398-406.

47. Cuzick J, Sestak I, Baum M et al. Effect of anastrozole and tamoxifen as adjuvant treatment for early-stage breast cancer: 10-year analysis of the ATAC trial. Lancet Oncol 2010; 11: 1135-1141.

48. Iwasa Z, Jinnai D, Koyama H, Sasano N. Second primary cancer following adjuvant chemotherapy, radiotherapy and endocrine therapy for breast cancer: a nationwide survey on 47,005 Japanese patients who underwent mastectomy from 1963-1982. Jpn J Surg 1986; 16: 262-271.

49. Murakami R, Hiyama T, Hanai A, Fujimoto I. Second primary cancers following female breast cancer in Osaka, Japan--a population-based cohort study. Jpn J Clin Oncol 1987; 17: 293-302.

50. Abu-Sbeih H, Ali FS, Tang T, Coronel E, Lee HJ, Pande M, Bresalier RS, Raju GS, Wang Y. Rate of colorectal neoplasia in patients with Hodgkin lymphoma. Colorectal Dis. 2020;22(2):154-160. PMID: 31541529

51. Hamzah Abu-Sbeih, Faisal S. Ali, Phillip S. Ge, Carlos H. Barcenas, Phillip Lum, Wei Qiao, Robert S. Bresalier, Manoop S. Bhutani, Gottumukkala S. Raju, Yinghong Wang. Patients with breast cancer may be at increased risk of colorectal neoplasia. Annals of Gastroenterology 2019; 32(4):400-406, PMID 31263363

52. Hamzah Abu-Sbeih, Ellie Chen, Osman Ahmed, Niharika Mallepally, Phillip Lum, Wei Qiao, Hun Ju Lee, Robert S. Bresalier, Lan Sun Wang, Brian Weston, Gottumukkala S. Raju, and Yinghong Wang. Patients with Non-Hodgkin's Lymphoma Are at Risk of Adenomatous Colon Polyps, Digestive Disease and Science, 2019;64(10):2965-2971. PMID: 31053975 